\title{
A Compact CPW-Fed UWB Antenna with Dual Band-Notched Characteristics
}

\author{
Aiting $\mathrm{Wu}^{1}$ and Boran Guan ${ }^{2}$ \\ ${ }^{1}$ School of Electronic Engineering, Xidian University, Xian 710071, China \\ ${ }^{2}$ Institute of Antenna and Microwave, Hangzhou Dianzi University, Hangzhou 310018, China
}

Correspondence should be addressed to Aiting Wu; wuaiting@hdu.edu.cn

Received 10 September 2013; Accepted 8 November 2013

Academic Editor: Guo Qing Luo

Copyright (C) 2013 A. Wu and B. Guan. This is an open access article distributed under the Creative Commons Attribution License, which permits unrestricted use, distribution, and reproduction in any medium, provided the original work is properly cited.

A compact CPW-fed planar UWB antenna with dual band-notched property is presented. The dual band rejection is achieved by etching a C-shaped slot on the radiation patch and two L-shaped parasitic strips in the ground plane. The experimental and measured results show that the proposed antenna exhibits an impedance bandwidth over an ultrawideband frequency range from 2.4 to $12.5 \mathrm{GHz}$ with VSWR less than 2, except for two stopbands at 3.3 to $3.75 \mathrm{GHz}$ and 5.07 to $5.83 \mathrm{GHz}$ for filtering the WiMAX and WLAN signals, respectively. It also demonstrates a nearly omnidirectional radiation pattern. The fabricated antenna has a tiny size, only $32 \mathrm{~mm} \times 32 \mathrm{~mm} \times 0.508 \mathrm{~mm}$. The simulated results are compared with the measured performance and show good agreement. The simple structure, compact size, and good characteristics make the proposed antenna an excellent candidate for UWB applications.

\section{Introduction}

Recently ultrawideband (UWB) communication systems have gained a great deal of attention due to their high data transmission rates, low consumption, good security, and immunity to multipath fading. Ever since 2002 when the US Federal Communication Commission (FCC) authorized the unlicensed use of UWB in the frequency band from 3.1 to $10.6 \mathrm{GHz}$ [1], a lot of research efforts have been put into UWB communication systems which led to a great demand of UWB antennas. As one of the promising candidates, CPWfed planar antennas have been investigated and reported in [2-6]. However, over the allocated frequency band, there are some existing narrow band services which may bring potential interferences to the UWB band, such as the IEEE 802.16 WiMAX system operating at 3.3-3.7 GHz and the IEEE 802.11a WLAN system operating at $5.15-5.825 \mathrm{GHz}$. To eliminate the interfaces antenna filtering technique has become an excellent candidate due to its simplicity, effectiveness, and low cost. Several methods have been proposed to design UWB antennas with band-notched functions, including etching Cshaped, L-shaped, T-shaped, H-shaped, U-shaped, E-shaped, and half-circle slots on the radiation patch or on the ground plane [7-15], or by employing T-shaped, L-shaped, and spiral parasitic strips or open circuit stubs to the antennas [16-20].

In this paper, a compact novel CPW-fed planar ultrawideband antenna with dual band-notched characteristics is proposed and investigated in detail. Compared with the previous published antenna structures [7-20], the height of the proposed antenna is very small, only $0.508 \mathrm{~mm}$, and its overall size is also quite compact, just $32 \mathrm{~mm} \times 32 \mathrm{~mm} \times$ $0.508 \mathrm{~mm}$. By etching a C-shaped slot on the radiation patch, a single band-notched UWB antenna is first designed. Moreover, by adding another two L-shaped parasitic strips on the ground plane, the dual band-notched property is obtained. The simulated and measured VSWR results indicate that the proposed dual band-notched antenna could operate from 2.4 to $12.5 \mathrm{GHz}$ with VSWR less than 2, except for two stopbands at 3.3 to $3.75 \mathrm{GHz}$ and 5.07 to $5.83 \mathrm{GHz}$ for filtering the WiMAX and WLAN signals. The simulated and measured radiation patterns of the proposed antenna are also presented. This paper is organized in the following 4 sections. In Section 2, the design and structure of the antenna are presented. Section 3 presents and analyses the simulated and measured results and further investigates the effect of the 


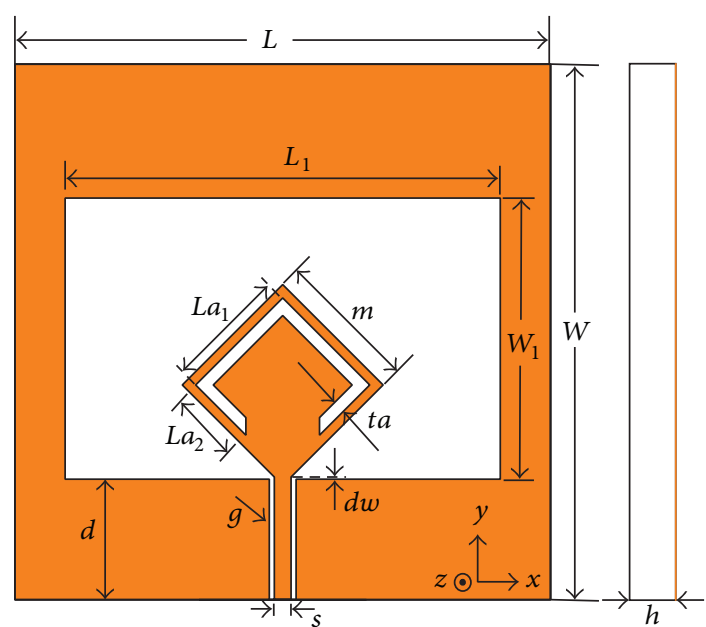

FIGURE 1: Geometry of the single band-notched antenna.

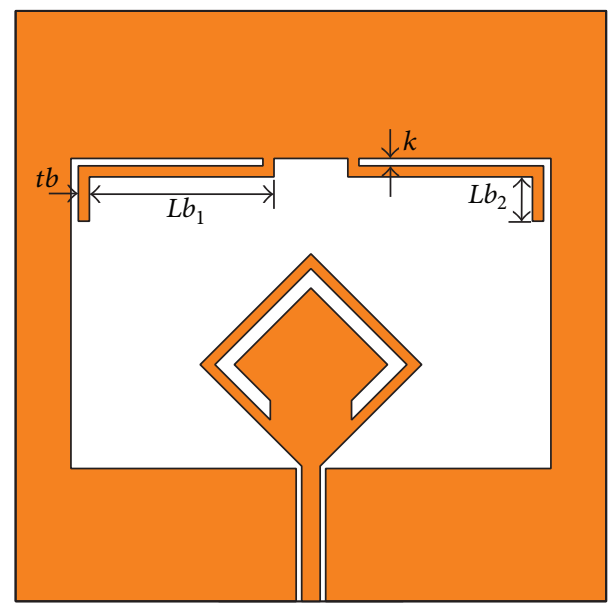

FIGURE 2: Geometry of the dual band-notched antenna.

antenna's geometry and dimensional parameters. Section 4 concludes the paper.

\section{Antenna Geometry}

2.1. Single Band-Notched UWB Antenna Design. Before developing the dual band-notched UWB antennas, we firstly design a $5.5 \mathrm{GHz}$ single band-notched UWB antenna, and its geometry and configuration are shown in Figure 1. The antenna prototype is fabricated on a Rogers 4350B substrate with a thickness equal to $h=0.508 \mathrm{~mm}$, a relative dielectric constant of $\varepsilon_{r}=3.66$, and a loss tangent of 0.0037 . The antenna is located in $x-y$ plane with the normal direction along $z$-axis. The dimension of the ground plane is $L$ by $W$ and the metal cladding is $0.018 \mathrm{~mm}$. It consists of a simple diamond patch connected to a CPW feed line, which excites a rectangular slot with a size $L_{1}$ by $W_{1}$. To ensure the characteristic input impedance is $50 \Omega$, the length of the coplanar line is set to $d$, the strip width is set to $s$, and the feed aperture is $g$. The feeding gap between the inner stub

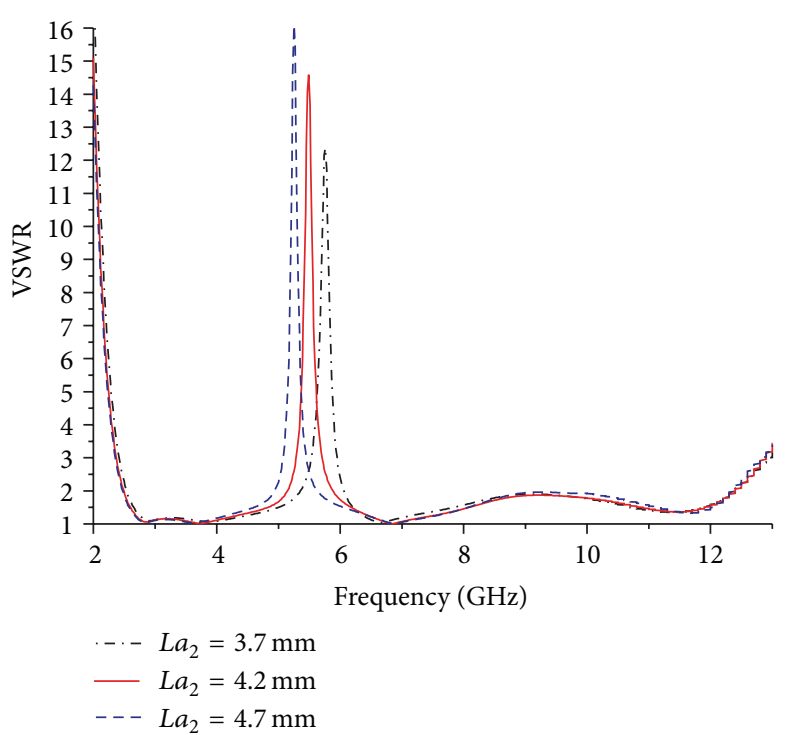

FIGURE 3: Simulated VSWR of the single band-notched antenna with various $L a_{2}$ values.

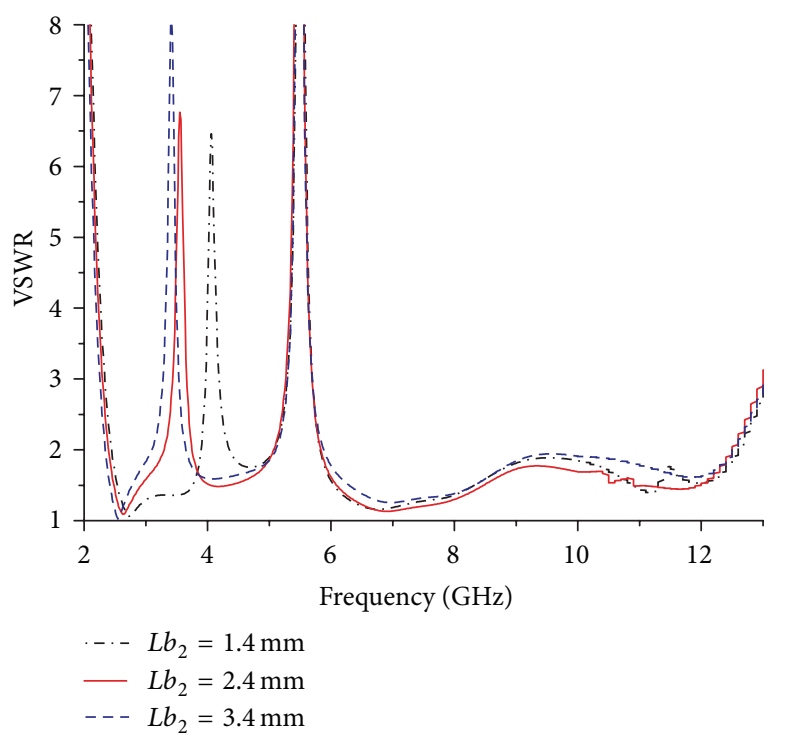

FIGURE 4: Simulated VSWR of the dual band-notched antenna with various $L b_{2}$ values.

and the edge of the coplanar line is denoted by $d w$, which has a significant impact on the impedance matching.

To obtain the notched band from 5.15 to $5.825 \mathrm{GHz}$, so that the antenna could avoid the interference with WLAN applications, a C-shaped slot is etched on the patch. The notched frequency generated by the $\mathrm{C}$-shaped slot could be empirically postulated as [10-14]

$$
f_{\text {notch }}=\frac{c}{4 L \sqrt{\varepsilon_{\text {eff }}}},
$$

where

$$
\varepsilon_{\mathrm{eff}}=\frac{\varepsilon_{r}}{3}
$$


TABLE 1: Optimized parameters of the single band-notched antenna.

\begin{tabular}{|c|c|c|c|c|c|c|c|c|c|c|c|c|}
\hline Parameters & $L$ & W & $L_{1}$ & $W_{1}$ & $d$ & $g$ & $s$ & $d_{w}$ & $L_{a_{1}}$ & $L_{a_{2}}$ & $m$ & $t_{a}$ \\
\hline Values (mm) & 32 & 32 & 26 & 16.8 & 7.2 & 0.3 & 1.4 & 0.3 & 7.1 & 4.2 & 7.8 & 1.05 \\
\hline
\end{tabular}

TABLE 2: Optimized geometry parameters of the two L-shaped strips.

\begin{tabular}{lcccc}
\hline Parameters & $L b_{1}$ & $L b_{2}$ & $k$ & $t_{b}$ \\
\hline Values $(\mathrm{mm})$ & 10 & 2.4 & 0.4 & 0.6 \\
\hline
\end{tabular}

$L$ is the total length of the $\mathrm{C}$-shaped slot, $\varepsilon_{r}$ is the relative dielectric constant, and $c$ is the speed of light. Besides the slot length, its position and width also have great effects on the band rejection performance and should be tuned carefully. Note that when the C-shaped slot is etched on the radiation patch, there is no other tuning work needed for the primitive antenna structure. The optimized parameters of the antenna geometry are listed in Table 1.

\subsection{Dual Band-Notched UWB Antenna Design. Besides} WLAN systems, WiMAX applications operating from 3.3 to $3.7 \mathrm{GHz}$ may bring interference to the UWB system as well. Based on the single band-notched antenna aforementioned, two L-shaped parasitic strips are added on the ground plane, and an extra $3.5 \mathrm{GHz}$ band-notched function is achieved. The geometry of the dual band-notched antenna is shown in Figure 2. All the dimensions are the same as those shown in Figure 1, except for adding two extra L-shaped strips. The geometry parameters of the strips on the ground plane are given in Table 2. A common method to generate dual bandnotched function is to etch two or more slots in the same patch [12-15], which may result in the complicated tuning process due to the mutual coupling effects of the slots. For the proposed antenna, the strips and the slot are totally independent for each other; thus the tuning process becomes much more simplified.

\section{Experimental Results}

3.1. Parameter Analysis. Both the single band-notched and the dual band-notched antenna prototypes are simulated and optimized using Ansoft HFSS software. Firstly the single band-notched antenna is simulated and investigated. The notched property is mainly determined by the length of the C-shaped slot $L a=2 *\left(L a_{1}+L a_{2}\right)$. With the value of $L a_{1}$ fixed, different values of $L a$ are got by varying the values of $L a_{2}$. Figure 3 shows the simulated VSWR result of the single band-notched antenna with different $L a_{1}$ values. As shown in the figure, by increasing $L a_{2}$ from $3.7 \mathrm{~mm}$ to $4.7 \mathrm{~mm}$, the notched frequency is shifted from 5.75 to $5.25 \mathrm{GHz}$.

For the dual band-notched antenna, the length of the parasitic strip $L b=L b_{1}+L b_{2}$ determines the other notched band. With the value of $L b_{1}$ fixed, different values of $L b$ are got by varying the values of $L b_{2}$. Figure 4 shows the simulated VSWR result of the dual band-notched antenna with different $L b_{2}$ values. As shown in the figure, by increasing $L b_{2}$ from

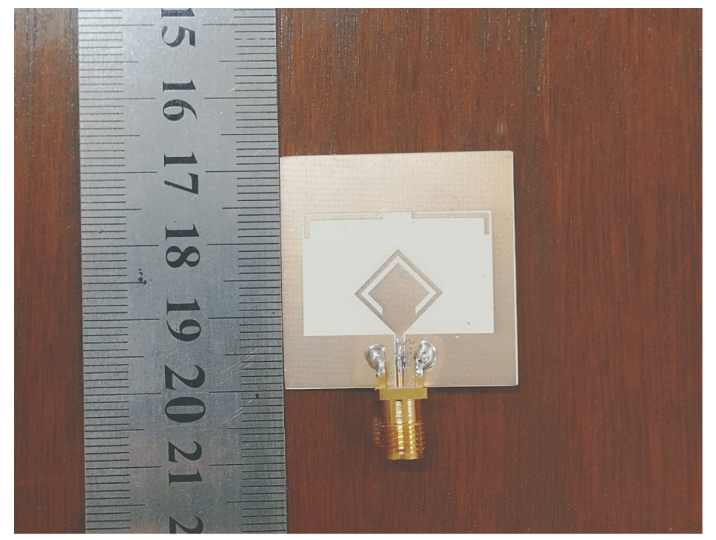

FIGURE 5: Photograph of the proposed dual band-notched antenna.

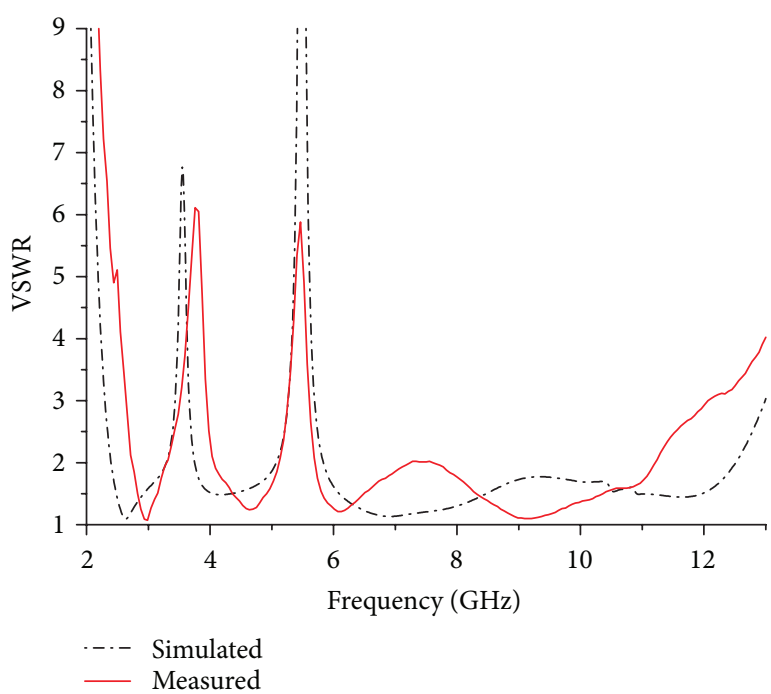

FIGURE 6: Simulated and measured VSWR of the proposed dual band-notched antenna.

$1.4 \mathrm{~mm}$ to $3.4 \mathrm{~mm}$, the second notched frequency is shifted from 4.05 to $3.4 \mathrm{GHz}$. It could be observed that the tuning of parameter $L b_{2}$ has little affection on the $5.5 \mathrm{GHz}$ notched band. Therefore the two notched bands could be tuned independently and no retuning work is needed for the antenna structure.

3.2. VSWR Results. To verify the design of the proposed antenna, a prototype of the dual band-notched antenna is fabricated and measured. Figure 5 shows the photograph of the fabricated antenna prototype. The antenna VSWR is measured by the Agilent 8719ES 50MHZ-13.5 GHz Network Analyzer. The antenna is fed through a SMA connector. The simulated and measured results of the VSWR results are 


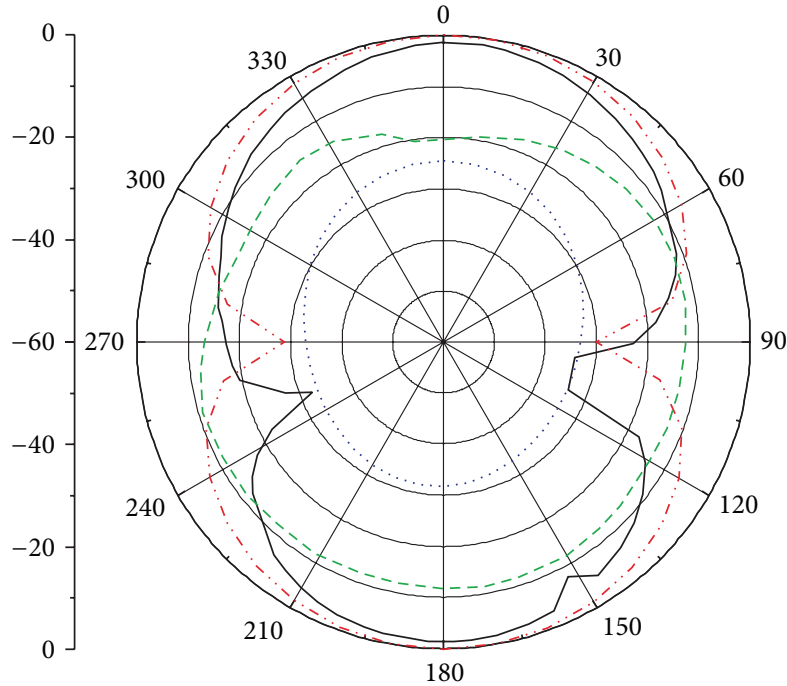

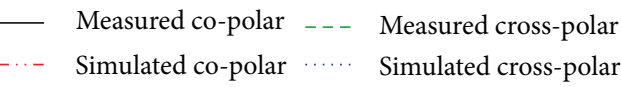

(a)

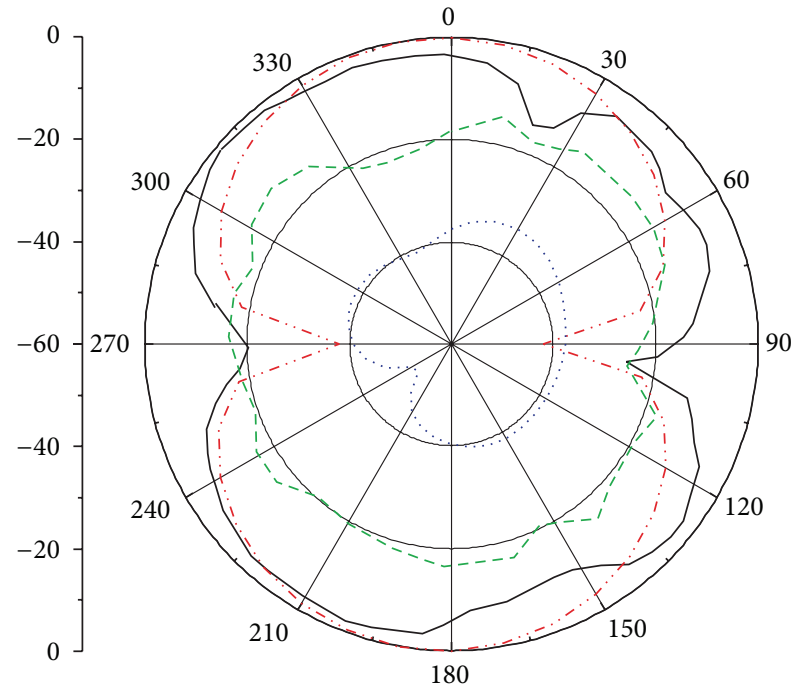

- Measured co-polar _ -- Measured cross-polar Simulated co-polar …... Simulated cross-polar

(b)

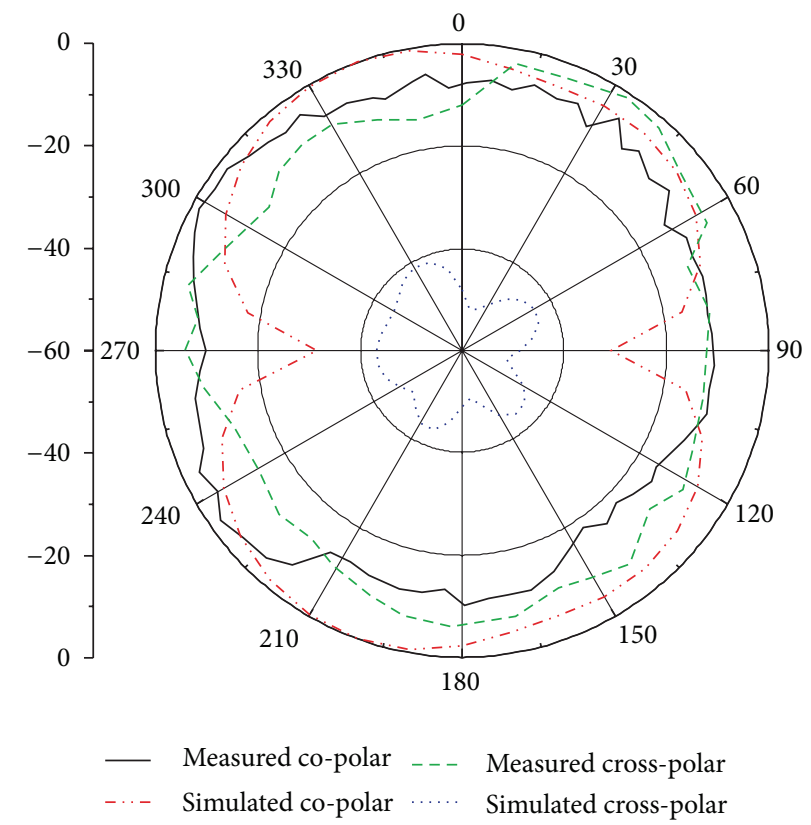

(c)

FIGURE 7: Simulated and measured E-plane radiation patterns at (a) $3 \mathrm{GHz}$, and (b) $6 \mathrm{GHz}$, (c) $9 \mathrm{GHz}$.

presented in Figure 6. As shown in Figure 6, the antenna impedance bandwidth extends from 2.4 to $12.5 \mathrm{GHz}$ with VSWR less than 2, except for two stopbands at 3.3 to $3.75 \mathrm{GHz}$ and 5.07 to $5.83 \mathrm{GHz}$. Thus it covers the whole UWB spectrum defined by FCC, which confirms the proposed antenna's good qualification for the UWB applications. It could be observed that there is a good agreement between the simulated and the measured results. The discrepancy between the simulated and the measured results might stem from SMA connector side effects and fabrication imperfections.
3.3. Radiation Pattern. Two planes are selected to show the radiation pattern of the proposed antenna, which are referred to as $x$ - $y$ plane or $E$-plane and $y$ - $z$ plane or $H$-plane, respectively. The simulated and the measured normalized radiation patterns of the antenna are shown in Figures 7 and 8 , both co-polar and cross-polar results presented, at 3, 6, $9 \mathrm{GHz}$. We could clearly see that the simulated and measured results have a good agreement with each other. It is also observed that the radiation patterns in $E$-plane are almost bidirectional at lower frequencies, while at higher ranges 


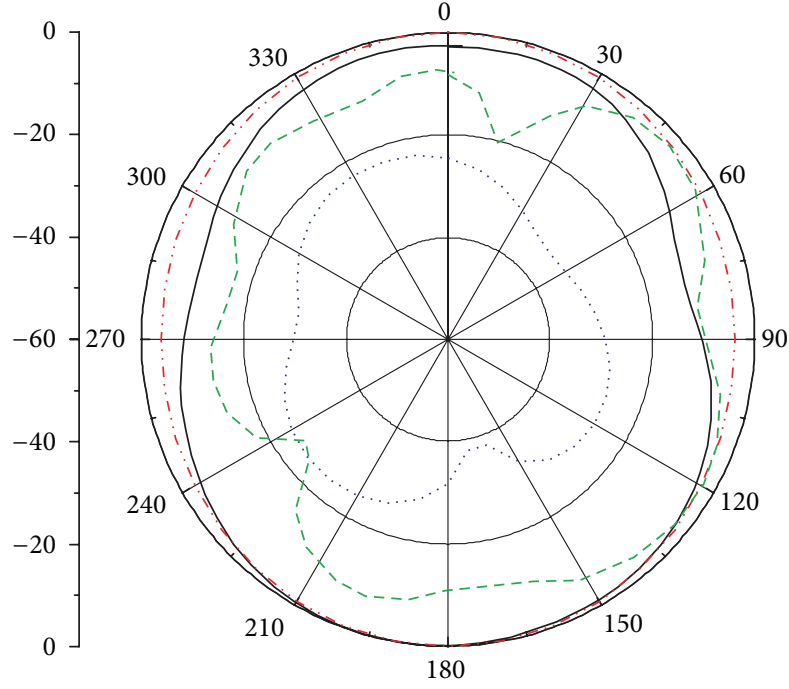

$\begin{array}{lll}\text { Measured co-polar } & --- & \text { Measured cross-polar } \\ \text { Simulated co-polar } & \cdots & \text { Simulated cross-polar }\end{array}$

(a)

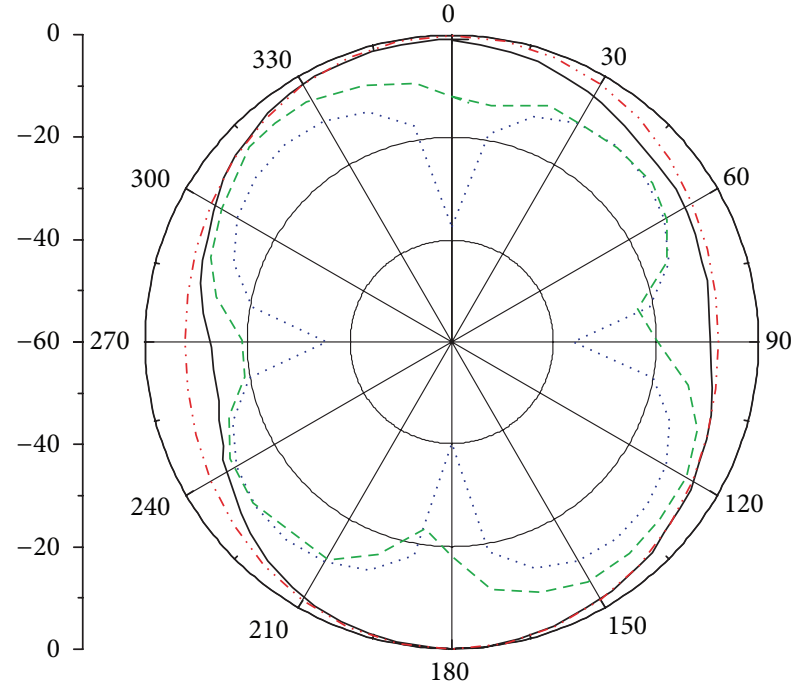

_ $\quad$ Measured co-polar _..- $\quad$ Measured cross-polar

(b)

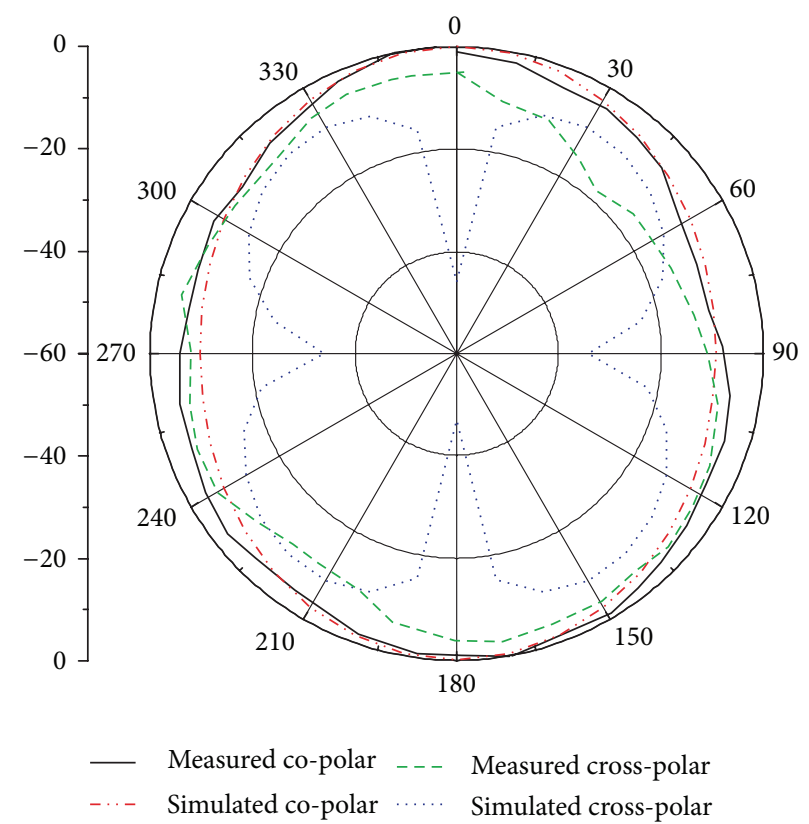

(c)

FIGURE 8: Simulated and measured $H$-plane radiation patterns at (a) $3 \mathrm{GHz}$, (b) $6 \mathrm{GHz}$, and (c) $9 \mathrm{GHz}$.

the radiation patterns are distorted. The $H$-plane radiation patterns conserve a clear omnidirectional characteristic at lower frequencies and vary a little at higher frequencies.

3.4. Current Distribution. Figure 9 shows the simulated surface current distributions at $3.5 \mathrm{GHz}$ and $5.5 \mathrm{GHz}$. The larger current distribution is indicated in red, while the smaller one is in blue. It is observed that the surface current is highly concentrated at the C-shaped slot at $3.5 \mathrm{GHz}$ and at the two L-shaped strips at $5.5 \mathrm{GHz}$, which means that a large portion of electromagnetic energy has been stored around the slot or the strips rather than being radiated into the air, so that the radiation efficiency decreases at the rejected bands.

3.5. Radiation Gain. The simulated gain of the proposed antenna is illustrated in Figure 10. A stable gain with the average of about $4.0 \mathrm{dBi}$ is obtained throughout the whole UWB operating band except at the two notched band frequencies. As desired, the antenna gain decreases sharply in the vicinity of 3.5 and $5.5 \mathrm{GHz}$, with the gain values about $-1.5 \mathrm{dBi}$ and 

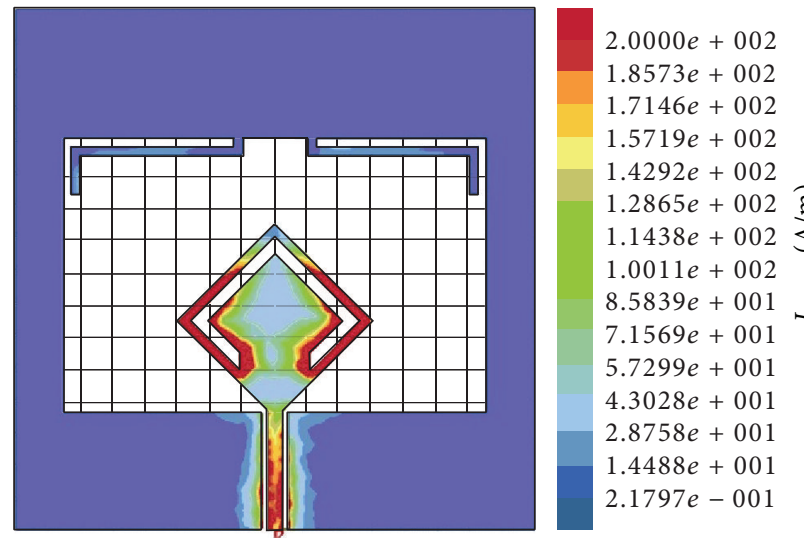

(a)

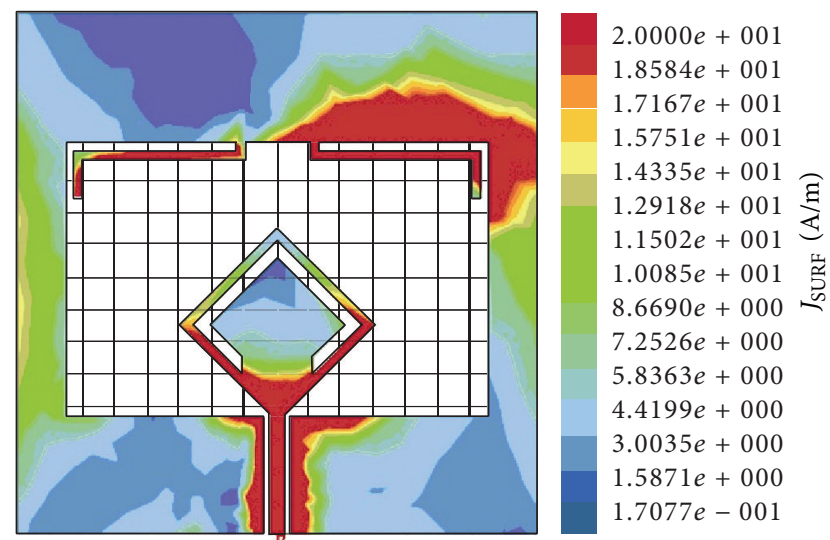

(b)

FIgURE 9: Simulated current distribution of the proposed antenna: (a) $3.5 \mathrm{GHz}$ and (b) $5.5 \mathrm{GHz}$.

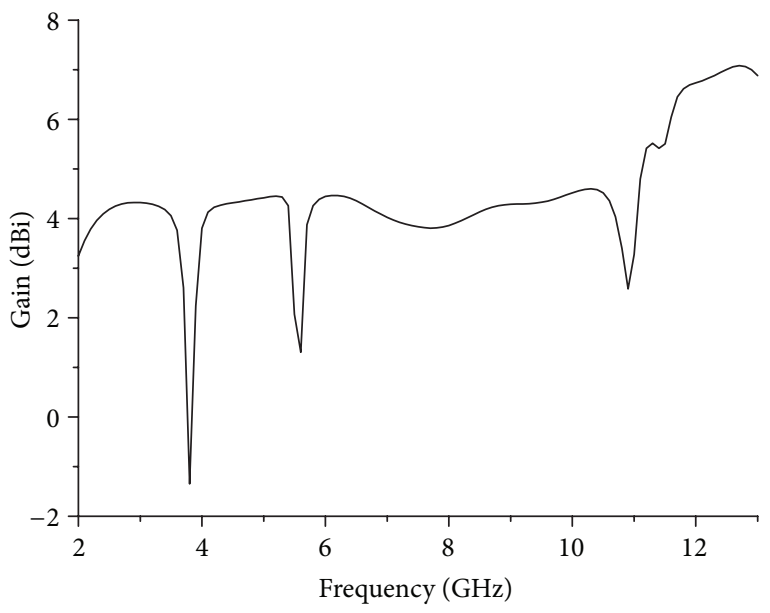

FIGURE 10: Simulated gain of the proposed antenna.

$1 \mathrm{dBi}$, respectively. It just demonstrates and reinforces the good band-rejected function of the proposed antenna.

\section{Conclusions}

A novel compact CPW-fed planar UWB antenna with dual band-notched property is proposed and investigated. The primitive UWB antenna is fed by a simple diamond patch, with a compact size of $32 \mathrm{~mm} \times 32 \mathrm{~mm} \times 0.508 \mathrm{~mm}$. The proposed antenna impedance bandwidth could cover the full UWB spectrum except for the two notched bands for WiMAX and WLAN applications, respectively. A C-shaped slot is etched on the patch and two parasitic strips are added to the ground plane to achieve $3.5 \mathrm{GHz}$ and $5.5 \mathrm{GHz}$ dual band-notched functions. The ultrawide bandwidth with dual band-notched characteristics, the compact size, and the simple structure of the proposed antenna make it an excellent candidate for UWB applications.

\section{Acknowledgment}

This work has been supported by the Zhejiang Provincial Department of Education Project under Grant no. Y201327468.

\section{References}

[1] Federal Communications Commission, "Revision of part 15 of the commission's rules regarding ultra-wideband transmission systems," First Report and Order, FCC 2 V48, 2002.

[2] R. Azim, M. T. Islam, and N. Misran, "Compact tapered-shape slot antenna for UWB applications," IEEE Antennas and Wireless Propagation Letters, vol. 10, pp. 1190-1193, 2011.

[3] H.-D. Chen, "Broadband CPW-fed square slot antennas with a widened tuning stub," IEEE Transactions on Antennas and Propagation, vol. 51, no. 8, pp. 1982-1986, 2003.

[4] S. T. Choi, K. Hamaguchi, and R. Kohno, "Small printed CPWfed triangular monopole antenna for ultra-wideband applications," Microwave and Optical Technology Letters, vol. 51, no. 5, pp. 1180-1182, 2009.

[5] M. Koohestani and M. Golpour, "Compact rectangular slot antenna with a novel coplanar waveguide fed diamond patch for ultra wideband applications," Microwave and Optical Technology Letters, vol. 52, no. 2, pp. 331-334, 2010.

[6] T. A. Denidni and M. A. Habib, "Broadband printed CPW-fed circular slot antenna," Electronics Letters, vol. 42, no. 3, pp. 135136, 2006.

[7] X.-F. Zhu and D.-L. Su, "Symmetric E-shaped slot for UWB antenna with band-notched characteristic," Microwave and Optical Technology Letters, vol. 52, no. 7, pp. 1594-1597, 2010.

[8] M. A. Habib, A. Bostani, A. Djaiz, M. Nedil, M. C. E. Yagoub, and T. A. Denidni, "Ultra wideband cpw-fed aperture antenna with wlan band rejection," Progress in Electromagnetics Research, vol. 106, pp. 17-31, 2010.

[9] S. Barbarino and F. Consoli, "UWB circular slot antenna provided with an inverted-L notch filter for the $5 \mathrm{GHz}$ WLAN band," Progress in Electromagnetics Research, vol. 104, pp. 1-13, 2010. 
[10] Y.-C. Lin and K.-J. Hung, "Compact ultrawideband rectangular aperture antenna and band-notched designs," IEEE Transactions on Antennas and Propagation, vol. 54, no. 11, pp. 30753081, 2006.

[11] N. Pouyanfar, "CPW-FED UWB antenna with band-stop properties," Microwave and Optical Technology Letters, vol. 55, no. 7, pp. 1533-1537, 2013.

[12] J. Xu, D. -Y. Shen, G. -T. Wang, X. -H. Zhang, X. -P. Zhang, and $\mathrm{K}$. Wu, "A small UWB antenna with dual band-notched characteristics," International Journal of Antennas and Propagation, vol. 2012, Article ID 656858, 7 pages, 2012.

[13] J. Liu, S. Gong, Y. Xu, X. Zhang, C. Feng, and N. Qi, "Compact printed ultra-wideband monopole antenna with dual bandnotched characteristics," Electronics Letters, vol. 44, no. 12, pp. 710-711, 2008.

[14] Q.-X. Chu and Y.-Y. Yang, "A compact ultrawideband antenna with 3.4/5.5 GHz dual band-notched characteristics," IEEE Transactions on Antennas and Propagation, vol. 56, no. 12, pp. 36373644, 2008.

[15] H. Zhai, J. Ou, T. Li, G. Li, L. Li, and C. Liang, "A compact ultrawideband antenna with two band-notches," Microwave and Optical Technology Letters, vol. 55, no. 3, pp. 583-586, 2013.

[16] W. X. Liu and Y. Z. Yin, "Dual band-notched antenna with the parasitic strip for UWB," Progress in Electromagnetics Research Letters, vol. 25, pp. 21-30, 2011.

[17] M. Ojaroudi and N. Ojaroudi, "Low profile slot antenna with dual band-notched function for UWB systems," Microwave and Optical Technology Letters, vol. 55, no. 5, pp. 951-954, 2013.

[18] C. -W. Zhang, Y. -Z. Yin, P. -A. Liu, and J. - Xie, "Compact dual band-notched UWB antenna with hexagonal slotted ground plane," Journal of Electromagnetic Waves and Applications, vol. 27, no. 2, pp. 215-223, 2013.

[19] M.-F. Wang, J.-X. Xiao, and S.-W. Wang, "Study of a dual-band notched wideband circular slot antenna," Journal of Electromagnetic Waves and Applications, vol. 24, no. 17-18, pp. 2445-2452, 2010.

[20] G.-M. Zhang, J.-S. Hong, and B.-Z. Wang, "Two novel bandnotched UWB slot antennas fed by microstrip line," Progress in Electromagnetics Research, vol. 78, pp. 209-218, 2008. 

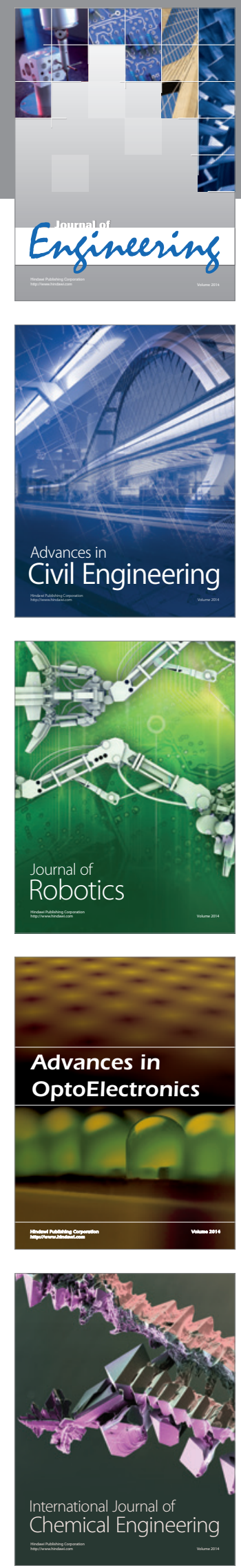

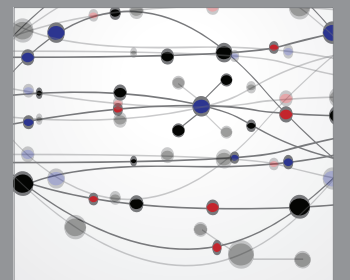

The Scientific World Journal
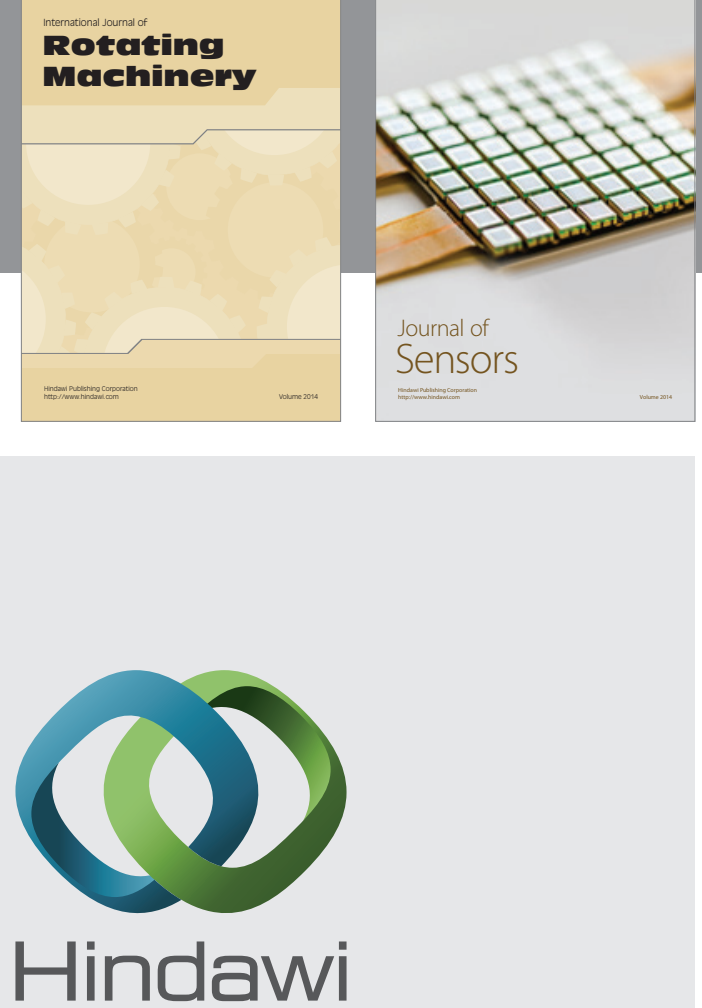

Submit your manuscripts at http://www.hindawi.com
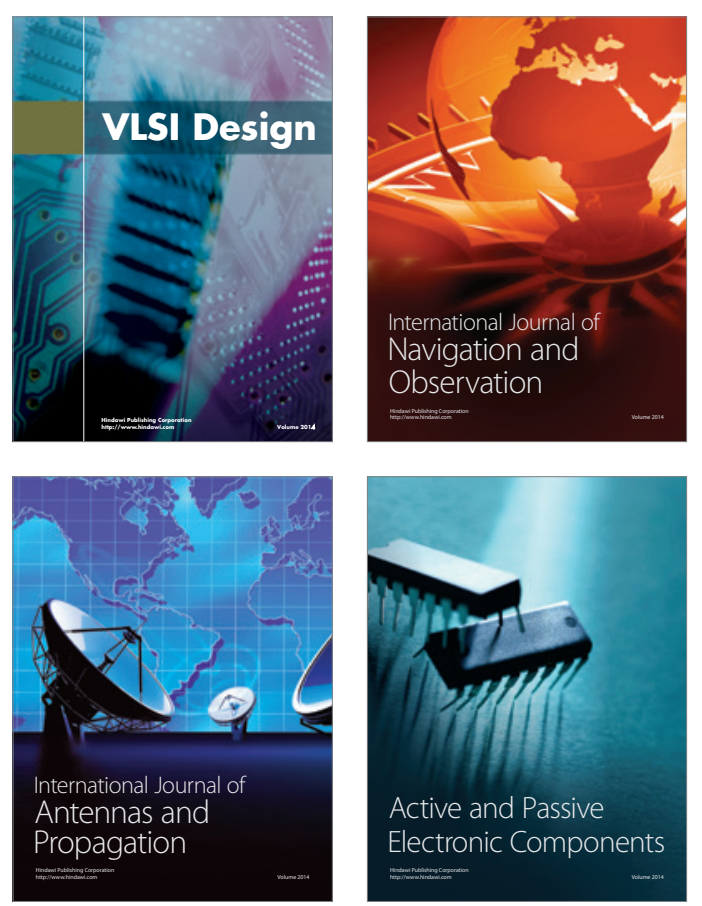
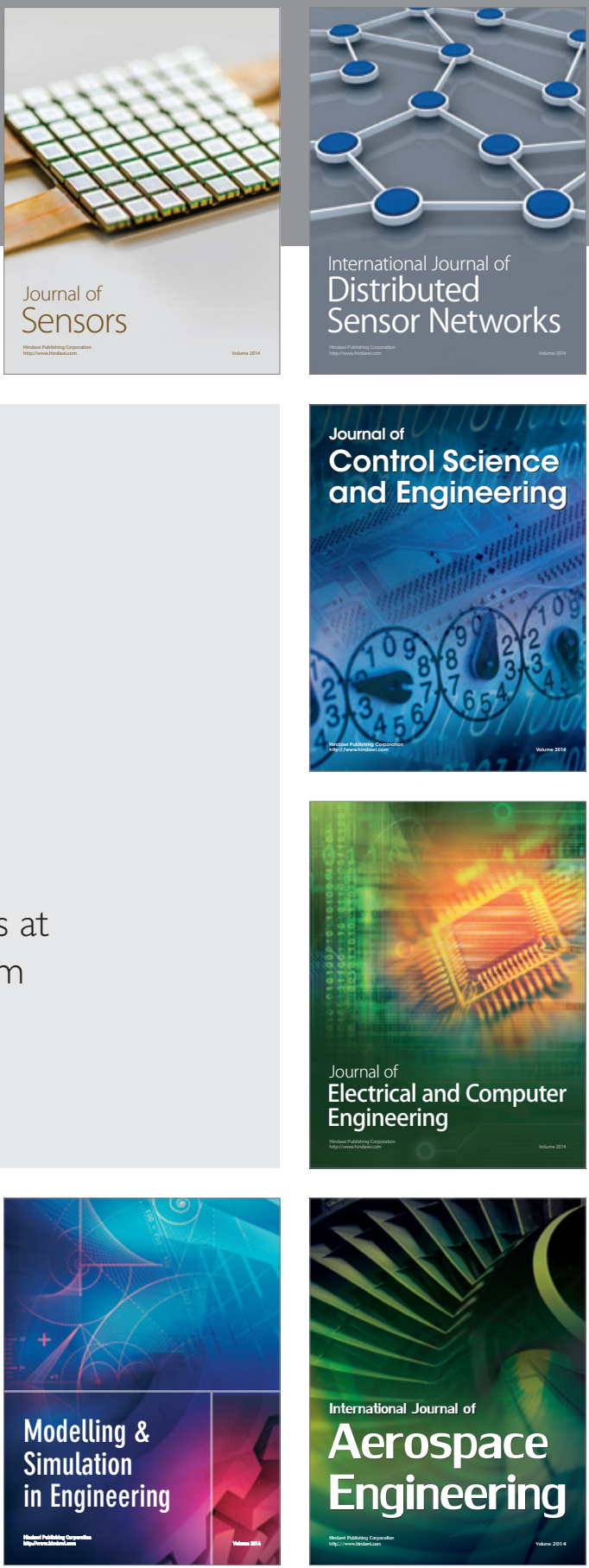

Journal of

Control Science

and Engineering
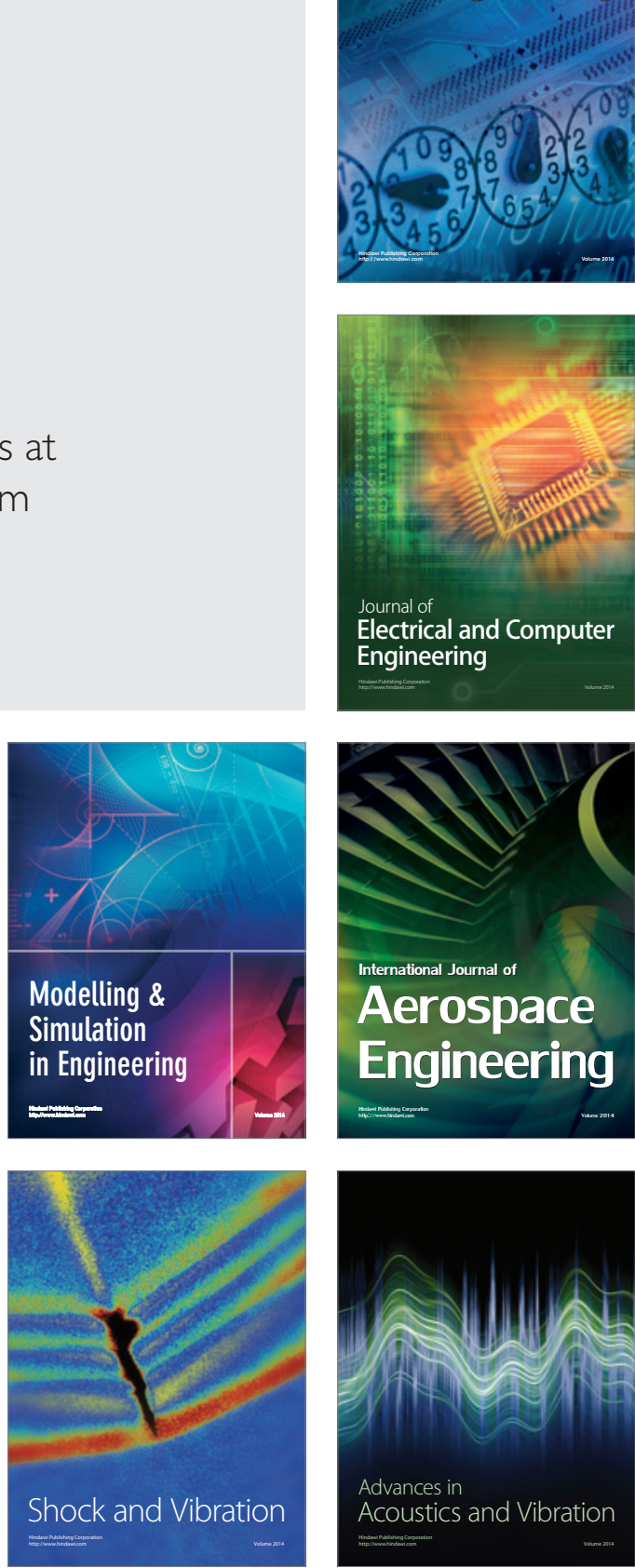